\title{
Microstructural Analysis of Football Texts
}

\author{
Sade Olagunju PhD \\ English Unit, Department of General Studies, Ladoke Akintola University of Technology, \\ P.M.B. 4000, Ogbomoso, Nigeria
}

\begin{abstract}
The paper investigates the microstructural elements in football texts. It explores the interclausal semantic relations of texts using van Dijk 1980 semantic macrostructures and Olagunju 2014 thoretical notion of microstructures of texts. Microstructural analysis involves not only the understanding of the sentential configuration of texts written separately but making connective inferences between the sentences and also integrating all sentences into a global representation of the meaning of the discourse. Microstructural analysis of text has to do with interclausal semantic relations which in turn realise the global semantic structure or macrostructures of text. van Dijk (1980:14) states that 'the function of microstructure is to organise complex (micro) information. Without them we would only be able to have a large number of links between information units of the local level and not to be able to form larger chunks that have their proper meaning and function'.
\end{abstract}

DOI: $10.7176 / \mathrm{JLLL} / 55-08$

Publication date: April $30^{\text {th }} 2019$

\section{Macrostructures and Microstructures of Texts}

The term macrostructure was introduced by van Dijk in 1973 and further developed into psychological notion of discourse comprehension by van Dijk and Kintsch (1983:242). Macrostructures, which are created by applying macrorules such as deletion, generalization and construction to a sequence of propositions derived from a text are global textual structures that give global meaning. The global meaning of discourse is represented by semantic macrorules. Semantic mappings which are also refered to as macrorules are used in relating microstructure with macrostructures. The function of macrorule is to reduce and organise information. That is, they delete and combine sequences of propositions. They are entailed by the sequence of propositions in the discourse, and also not only generate one but several macrostructures at increasingly more global levels of semantic representation. It is to be noted that no proposition may be deleted which is a presupposition for a subsequent (macro) proposition in the discourse. In essence, microstructures are processed into macrostructures by application of the macrorules. Meanwhile, Sadeghi (2013:1) in his work on fictional discourse states that it is possible to interpret or use many phenomena as 'whole' (macrostructure), as cognitive units of some kind, with respect to the various parts, sections or elements (microstructure) of the whole objects. Sadeghi (ibid) notes further that macrostructure could be considered a plot, summary or a large-scale statement of the content of a text.

van Dijk (1986: 33 -34) refers to the three macrorules as follows:

Deletion rules: At the initial stage, deleting 'all information that is no longer relevant in the rest of the text, such as local details.'

Generalisation rules: Replacing a sequence of propositions by one generalisation

Construction rules: At the final stage, replacing 'a sequence of propositions that denote the usual event as episode by one macroproposition that denotes the act or event as a whole.

According to van Dijk (1986:32), a macrostructure consists of numerous macropropositions, such that the whole macrostructure is organised hierarchically with each sequence of macro propositions subsumed under a higher level of macroproposition. In essence, some form of summarisation of content of text is involved at the macrostructural level. There are rules guiding the sequence of propositions into smaller sets. These are refered to as macrorules.

According to Louwarse and Graesser (2006:9), macrorules operate recursively which makes the macrorules that are formed to be subject to another cycle of macrorules. Macrostructures are therefore seen as abstract semantic descriptions of the semantic content of the text. In order to dymistify this concept, van Dijk and Kintch (1983) note that in addition to textual macrostructures, there is need for pragmatic superstructure and schematic structure similar to the rhetorical structure of texts.

Macrostructure consists of the internal organisation of texts at a level that is wider than microstructures. Microstructures have to do with the local structure of words, clauses, sentences or turns in conversations. Louwerse and Graesser (2006:9) note that macrostructures may be derived from microstructures by abstracting or summarising specific details, etc. Texts are usually structured both locally (connection between clauses and sentences) and globally (connecting larger fragments of discourse such as paragraphs). The microstructure can also be realised through the syntactic rules, the meaning of the words in sentences etc.

In his work on text structure, Hutchins (2002:3) states the three basic aspects of text structure which are 
microstructure, macrostructure and superstructure (schemata). To him, microstructure refers to relationships within sentences and between adjacent sentences or clauses. He sees macrostructure as the relationship between blocks of sentences (i.e paragraphs) and large text segments. The superstructure refers to the functions of text segment within the text as a whole and its overall organisation as a coherent text. Superstructures are conventional schemas which provide the global form for the macrostructural content of discourse. In other words, macrostructure deals with content and superstructure with form.

van Dijk and Kintsch (1983:242) however note that the superstructure 'provides a kind of overall functional syntax for the semantic macrostructures'. Examples of these are prevalent in news discourse with superstructural categories such as headlines, lead, context etc.

In summary, Eggins and Slades (1997:57), following Martin (1984), note that the overall staging patterning of texts is the schematic structures. In this work however, we have limited our analysis of the textual and internal configuration of the selected texts to the macrostructure and microstructures for a schematic representation of the text.

\section{Approaches to Text Analysis}

Many scholars have analysed 'text' using different approaches. For example, Olateju and Yusuf (2006) describe text by utilising discourse analytical techniques and functional approaches; Adegbija (1995) and Odebunmi (2008) describe texts from the pragmatic perspective; Lawal (1997) and Osisanwo (2001) utilise the stylistic approach, while Adegbite (1991), Adegbite and Ajayi (1995) analyse some specific texts using both text grammar and pragmatic approaches. Olagunju (2004) and Olagunju and Ogunleye (2007), in her work on text analysis, utilised the functional approach to analyse literary and biblical texts respectively. These scholars have in no small way contributed to the analysis of texts especially in ESL settings.

The approaches to text analysis earlier mentioned cannot be over-emphasised because these call for the dynamic interpretation of texts and also help in revealing the choices made by writers from the bundles of stylistic choices that language presents. There are other approaches to text analysis and are all useful for proffering solution to how best text can be understood, interpreted and constructed.

\section{Research Methodology}

In this study, copies of two selected Nigerian newspapers namely; Sporting Life and Complete Sports were collected for a period of one month of 2010 world cup tournaments. 60 newspapers were collected and the lead articles on each of the newspapers were read for the purpose of the study. Of these, 15 lead articles were purposively selected from each of the two newspapers. We have 30 lead articles altogether from Sporting Life and Complete Sports and each of these newspapers were categorised as Text A and B respectively. Microstructural analysis was done on the contents of the selected articles utilising van Dijk (1980) macrostructure and Olagunju (2014) notion of microstructure of texts. Secondary source of data include books, journal article and the internet.

\section{Data Analysis and Discussion}

In textual analysis, we have macrostructural and microstructural units that work together to give the global textual resources. It is within this notion that Olagunju (2014) discovered the following ten macrostructural elements in written football reports. Title [T], Preamble [P], Online Thesis [OT], Online Thesis Expatiation [OTE] Voice Insertion (VI), Offline Thesis Insertion (OTI), Offline Thesis Expatiation (OFTE), Evaluation (Eva), Prediction (Pre) and Winding Up (WUp).

However, the present study aims at investigating the texts at micro level to further discover the interrelatedness and semantic relations of the clauses at the micro unit of textual analysis. The following microstructural elements are noted in the data: First Person Focus, Third Person Focus, Substantiating Element, Concessive Element, Declarative Element, Approbative Element and Pejorative Element. Each of the identified microstructures will be explained subsequently because they provide the basis for the analysis of microstructure of texts.

First Person Focus (FPF): This refers to a microstructural element which has to do with a narrative mode that involves the direct utterances of participants in the discourse. In sports reports, the use of the direct utterances of participants by inserting their voices show that the writer wants to reveal that he gets an account of the event(s) from the primary sources. First person focus is characterised by the use of first person pronouns such as 'I' and its plural form 'we'. In the mechanics of sports reports studied, first person focus is characterised with the use of 'I' and 'we' as earlier mentioned and their objective cases 'me' and 'us'.

Third Person Focus (TPF): This microstructural element is identified by third person focus marker in discourse such as 'he', 'she' and 'they' and also their objective cases 'him', 'her', and 'them'. Third person focus as a semantic structure also involves the use of linguistic elements that those pronouns may be referring to as their antecedents in the preceding sentences. Also, some other markers of the third person focus include the use of 
proper nouns, nominal phrases etc. This microstructural element is employed whenever the writer wants to detach himself from the story by remaining as the outside voice but revealing the actions of the participants in the discourse.

Substantiating Element (SE): This is a microstructural element of text that gives elabourate details of the preceding clauses in the interclausal relations of texts. Substantiating elements are not commonly found in simple sentences but compound, multiple or complex sentences or at the macro level of textual segments. The writer may substantiate by using additive elements or linguistic properties that denote or imply substantiation.

Concessive Element (CE): This is a microstructural element of text that denotes textual elements that are marked by concessive subordinators (although, whereas, while), concessive coordinators (although, but), concessive adverbial items (nevertheless, nonetheless, all the same, even so, still, yet, after all), and concessive prepositions (in spite of, despite, notwithstanding). It is to be noted that concessive elements of text are significant to the notion of text connectivity. The condition stated as markers of concessive element is based on context of use in the interclausal semantic explorations.

Declarative Element (DE): This microstructural element of text has to do with the notion of making a statement. Statements are clauses or sentences primarily used to convey information and usually contain a subject and a predicator. A declarative element carries the main information or message of the text. It is associated with the title - a sign post of the text and the first macrostructural element of text.

Approbative Element (AE): This is a microstructural element of text which denotes a positive effect. It expresses appreciation, approval, or praise. This element is associated with evaluation in discourse structure. Meanwhile, it is to be noted that evaluation in discourse context has to do with the expression of one's personal attitude, commentary, perspective or perception.

Pejorative Element (PE): A pejorative element refers to textual microstructure that is meant to express a negative opinion or evaluation. Pejorative contents are semantic contents of the text. They are usually associated with evaluation at the macro level of textual structure. Pejoratives may involve derogation which may bring offense to the intended target person or group. It is all about expressing negative judgments whose interpretations depend on contextual background belief of the discourse participants.

\section{Microstructural Analysis of Text A (Sporting Life)}

This section is devoted to the microstructural analysis of text A. The analysis is done to show different levels of text structure. The interclausal semantic relations of text A and their pragmatic implications are presented and discussed below.

\begin{tabular}{|l|l|r|r|r|r|r|r|c|}
\hline \multirow{2}{*}{ Text A1 } & \multicolumn{6}{|c|}{ Macrostructures } & \multicolumn{7}{c|}{ Microstructures } \\
\cline { 3 - 9 } & & FPF & TPF & CE & SE & DE & AE & PE \\
\hline 1. & Title & - & - & - & - & 1 & - & - \\
\hline 2. & Preamble & - & 1 & 1 & - & - & - & - \\
\hline 3. & Online Thesis & - & 1 & - & 1 & - & - & - \\
\hline 4. & Online Thesis Expatiation & - & 3 & - & - & - & - & - \\
\hline 5. & Offline Thesis Insertion & - & 5 & - & 1 & - & - & - \\
\hline 6. & Offline Thesis Expatiation & - & 4 & 1 & 2 & - & - & - \\
\hline & Total & 0 & 14 & 2 & 4 & 1 & 0 & 0 \\
\hline
\end{tabular}

Table 1: Microstructural Analysis of Text A1

Below are the microstructural elements in Text A1.

1. Title: AHEAD NIGERIA VS GREECE: Wenger Tracks Down Enyeama /(DE)

2. Preamble: Super Eagles' goalkeeper Vincent Enyeama could be moving closer to wearing the jersey of Barclays English Premier League side Arsenal FC of London next season/(TPF) if he replicates the stunning show he exhibited against Argentina at the Ellis Park Stadium in Johannesburg last Saturday, tomorrow against Greece./(CE)

3. Online Thesis: Sporting Life gathered from a top dog of the Nigerian football Federation (NFF) at the Raddisson Hotel in Johannesburg on Tuesday night that Arsenal manager Arsene Wenger, who resides there, made enquires about Enyeama's true age, his conduct on and off the pitch/(TPF) and a detailed statistics of his playing career./(SE)

4. Online Thesis Expatiation: Wenger confided in the Nigeria soccer buff that his agents who watched Enyeama against Argentina spoke highly of the Nigerian player's talents, composure when put under pressure and his amazing reflexes./(TPF) The king of the dugout in England consequently decided to sniff out information on Enyeama just he has decided to watch the Nigerian in the game against Greece to ascertain his level of consistency during matches./(TPF)

Sporting Life had exclusively broken the story that Enyeama market value had risen to 3 million Euros (about N591 million) on Monday/(TPF) and it appears that a stingy Wenger may cough out that sum for the Nigerian if 
he impresses against Greece./(SE)

5. Off line Thesis Insertion (i): Interestingly, Enyeama has confirmed that he had to switch off his phone from the day he was listed in Nigeria's 44-man squad to enable him to concentrate on the task of improving his skilled/(TPF) and only talked with his family using public telephones./(SE)

6. Offline Thesis Expatiation (i): He revealed further that he bought tapes on some of the best stars in Europe who are in South Africa to study their movement and how they beat goalkeepers to score goals and had closely taken down the notes that he hoped will guide him in the event that they played against Argentina. It remains to be seen/(TPF) if Wenger keeps his words of watching the Nigerian against Greece./(CE) But what appears to be fact is that Arsenal's radar have Enyeama in their sights/(SE) and it would quite remarkable/(TPF) if another Nigerian plays for the Gunners after Nwankwo Kanu's remarkable stay at the Emirates stadium./(CE)

Offline Thesis Insertion (ii): Curiously, Arsenal will make Joe Cole their highest earner after the World Cup as they prepare to beat off competition from Manchester United and Tottenham Hotsur, according to reports in Johannesburg on Tuesday night./(TPF)

Offline Thesis Expatiation (ii): Also, Wenger looks set to step his interest in Everton midfielder Steven Pianear after the World Cup./(TPF)

Offline Thesis Insertion (iii): "Pianear has grown this year,/(TPF) he was usually a very busy player where the final ball was missing a little bit,/(TPF) but this year he has gained in personality and he has kept his workrate, so he has been much more efficient" Wenger said of the South African./(TPF)

Offline Thesis Expatiation (iii): "What also played a big role in his growth was that Mikel Arteta was not there for a while/(TPF) and that he had to take the responsibility as the playmaker of the team". /(SE) (Sporting Life, June 16, 2010).

From the table, it is observed that the third person focus (TPF) dominates the text. It is realised in all the microstructures except the title. Next to the third person focus in degree of occurrence is the substantiating element. Concession element also features in the text and there is an instance of the declarative element. It is to be noted that the first person focus, approbative element and pejorative element did not feature in the text. The non-occurrence of these elements could be attributed to the non-occurrence of the macrostructural elements that these microstructures are associated with. These macrostructural elements are voice insertion and evaluation.

Meanwhile, the identification of the third person focus in this particular text requires the understanding of linguistic properties that denote the third person focus as a microstructure of the text. There are, however, few instances where the writer uses some of the markers of third person focus such as the third person pronoun 'he' and proper nouns such as 'personal names' in the text.

\begin{tabular}{|l|l|r|r|r|r|r|r|c|}
\hline \multirow{2}{*}{ Text A2 } & \multicolumn{1}{|c|}{ Macrostructures } & \multicolumn{7}{c|}{ Microstructures } \\
\cline { 3 - 9 } & & FPF & TPF & CE & SE & DE & AE & PE \\
\hline 1. & Title & - & - & - & - & 1 & - & - \\
\hline 2. & Preamble & - & 1 & - & 1 & - & - & - \\
\hline 3. & Online Thesis & - & 1 & - & 1 & - & - & - \\
\hline 4. & Online Thesis Expatiation & 2 & 2 & - & 1 & - & - & - \\
\hline 5. & Voice Insertion & 7 & 2 & - & - & - & - & - \\
\hline 6. & Prediction & 5 & 1 & - & - & - & - & - \\
\hline \multicolumn{2}{l}{ Total } & 14 & 7 & 0 & 3 & 1 & 0 & 0 \\
\hline
\end{tabular}

Table 2: Microstructural Analysis of Text A2

Below are the microstructural elements identified in Text A2.

1. Title: LAGERBACK MOURNS: My Boys Went to Sleep /(DE)

2. Preamble: Nigeria senior national team's technical adviser Lars Lagerback lamented the poor marking from the Nigerian lads in the sixth minute from an Argentina corner-kick taken by Lionel Messi/(TPF) and headed into the Super Eagles' unguarded goalpost for the goal that differentiated both countries in one of the Group D opening matches at the Ellis Park stadium on Saturday./(SE)

3. Online Thesis: At the post-match conference held in Johannesburg on Saturday Lagerback stated that his boys went to sleep whilst defending the corner-kick that resulted in the goal,/(TPF) but praised them for producing a superb outing against one of the best set of players in the World despite the team's late preparations for the 2010 World Cup./(SE)

4. Online Thesis Expatiation: "Sadly, my boys went to sleep when defending the corner-kick./(TPF) Against a World class team like Argentina, you get punished when you make such silly mistakes./(TPF) I'm pained because I have seen these boys respond absolutely well to set pieces in training/(FPF) and in the three friendly games that we played before this./(SE) I was therefore shocked that they went to sleep after all that we did in training on such set-pieces./(FPF)

5. Voice Insertion (i): “I'm disappointEd./(FPF) I'm also proud of the players./(FPF) I'm disappointed by the results./(FPF) It was a game that we could have won./(TPF) We created goal scoring chances that were not 
convertEd./(FPF) The goal came from a mistake from one of my defenders that resulted in the corner kick./(TPF) 6. Prediction: "We are not out of the World Cup yet./(FPF) We will go back and correct the mistake that we have seen/(FPF) and I know the spirit in the boys that they would surely beat Greece./(FPF) We will come out a better side against Greece,/(FPF) and then we can take the remaining games as they come,"/(FPF) he said./(TPF) Asked what the injury sustained by Taiye Taiwo leading to his substitution was like, Lagerback said:/(TPF)

Voice Insertion (ii): "I have not seen or spoken to Taiwo or the medical men to know what his injury is like./(FPF) I hope that he would be fine for the next game against Greece./(FPF) Until I speak to the doctors and indeed Taiwo, I cannot tell you if he is out of the next game."/(FPF) (Sporting Life, June 13, 2010)

From the microstructural analysis of text A2, the table shows that the first person focus (FPF) predominates the text. Third person focus is next to the first person focus in terms of frequency and also, next to the third person is the substantiating element. The text exhibits only one instance of the declarative element.

Furthermore, the dominance of the first person focus can be attributed to the occurrence of voice insertion at the macro level of text. The First person focus is largely associated with voice insertion signifying 'on sight' participation and narration of events. The writer here quotes directly, the voice of the discourse participant in the text. Mostly, what realises the first person focus in the text is the use of first person pronouns 'I' and 'We'. It is to be noted that concession element, approbative element and prejorative element did not feature. The nonfeaturing of pejorative and approbative element could be attributed to the absence of evaluation in the text structure.

\begin{tabular}{|l|l|r|r|r|r|r|r|c|}
\hline \multirow{2}{*}{ Text A3 } & \multicolumn{1}{|c|}{ Macrostructures } & \multicolumn{6}{c|}{ Microstructures } \\
\cline { 3 - 9 } & & FPF & TPF & CE & SE & DE & AE & PE \\
\hline 1. & Title & - & - & - & - & 1 & - & - \\
\hline 2. & Preamble & 2 & 4 & - & - & - & - & - \\
\hline 3. & Online Thesis & - & 1 & - & - & - & - & - \\
\hline 4. & Online Thesis Expatiation & - & 2 & - & 2 & - & - & - \\
\hline 5. & Voice Insertion & 2 & 2 & - & - & - & - & - \\
\hline 6. & Winding Up & - & 1 & - & - & - & - & - \\
\hline
\end{tabular}

Table 3: Microstructural Analysis of Text A3

Below are the microstructural elements identified in Text A3.

1. Title: Eagles Set for Match of Their Lives /(DE)

2. Preamble: The Super Eagles say today's crunch FIFA World Cup Group B clash with Korea Republic in Durban is unarguably the match of their lives./(TPF) "We can't lose;/(FPF) we must not lose"/(FPF), said captain Nwankwo Kanu as the team concluded its last training ahead of the big match./(TPF) Defenders Taye Taiwo and Elderson Echiejile,who left the battle field injured against Greece in Bloemfontein on Thursday, trained fully with the rest of the squad, meaning coach Lars Lagerback has a full team to choose from on Tuesday evening./(TPF)

3. Online Thesis: Nigeria must win then hope that Argentina expectedly overpower Greece in Polokwane in a match starting simultaneously for the Super Eagles to reach the Round of 16 of Africa's first- ever FIFA World Cup./(TPF)

4. Online Thesis Expatiation: Korea Republic, with three points, need only a draw in tonight's game to proceed to the Round of 16 provided Argentina beat the Greeks./(TPF) But the Nigeria camp is not looking at elimination now and the players are determined to prove their mettle at this critical period./(SE) Most of them are playing in their first FIFA World Cup final as Nigeria failed to qualify for the last championship in Germany,/(TPF) and they have no wish to leave the stage so early./(SE)

5. Voice Insertion: Kanu continued:/(TPF) "Our objective is dear:/(FPF) We will go all out for victory./(FPF) But as a matured team, we will not do that at the expense of curtailing./(FPF) We have to play a careful game and at the same time be very offensive./(FPF) It is going to be exciting"./(TPF)

6. Winding Up: The team trained at their Umhlathuze sporting complex, Richards Bay ground on Monday afternoon before leaving for Durban by road around 4pm./(TPF)(Sporting Life, June 22, 2010)

In text $\mathrm{A} 3$, the writer uses the third person focus across the macrostructures with the exception of the title where the declarative element features. First person focus that features is next in occurrence to the third person focus. It is to be noted that substantiating element also features in the text while the concessive element does not feature at all. The non-occurrence of approbative element and pejorative elements is as a result of the nonfeaturing of evaluation at the macro level of textual structure. 


\begin{tabular}{|l|l|r|r|r|r|r|r|c|}
\hline \multirow{2}{*}{ Text A4 } & \multicolumn{1}{|c|}{ Macrostructures } & \multicolumn{9}{c|}{ Microstructures } \\
\cline { 3 - 9 } & & FPF & TPF & CE & SE & DE & AE & PE \\
\hline 1. & Title & - & - & - & - & 1 & - & - \\
\hline 2. & Preamble & - & 1 & - & - & - & - & - \\
\hline 3. & Online Thesis & - & 1 & - & - & - & - & - \\
\hline 4. & Online Thesis Expatiation & - & 3 & - & 1 & - & - & - \\
\hline 5. & Voice Insertion & 2 & 1 & - & - & - & - & - \\
\hline 6. & Evaluation & - & 4 & - & - & - & 2 & 1 \\
\hline 7. & Winding Up & 2 & 2 & - & & - & - & - \\
\hline & Total & 4 & 12 & 0 & 1 & 1 & 2 & 1 \\
\hline
\end{tabular}

Table 4: Microstructural Analysis of Text A4

Below are the microstructural elements identified in Text A4

1. Title: NIGERIA, S/KOREA FALL-OUT: Lagerback Bemoans Korea's Tactics /(DE)

2. Preamble: Nigeria coach Lars Lagerback accused South Korea of time wasting as his team tumbled out of the World Cup finals on Tuesday./(TPF)

3. Online Thesis: The Super Eagles could only draw 2-2 in Durban, a result which meant Lagerback's side finished bottom of Group B./(TPF)

4. Online Thesis Expatiation: Nigeria had look little they could be making an unlikely passage into the second round after Kalu Uche put them into a 12th minute lead./(TPF) But headed goals from Lee Jung-Soo and Park Chu-Young put the South Koreans back in the driving seat and not even an Yakubu Aiyegbeni's penalty was enough./(SE)

Time ran out as the African nation pressed for a decisive winner that would have put them in second place and Lagerback said their opponents had played down the clock to help secure the draw./(TPF)

5. Voice Insertion: He said:/(TPF) 'I was a little bit sorry about all the time wasting./(FPF) I don't think it's fair play./(FPF)

6. Evaluation: "It's very disappointing/(TPF) and I think the (Nigeria) players have done really well."/(AE) The manager can have few complaints about his team's exit, however, given the profligacy his strikers in front of goal./(TPF) Yakubu was the worst culprit - missing from no more than four yards out with the entire goal gaping,/ (PE) the Everton striker only succeeding in prodding the ball wide./(TPF)Substitute Obafemi Martin also should have done better when put through/(AE) and Lagerback was reflective on missed opportunities./(TPF) 7. Winding Up: And the 61-year-old Swede offered his congratulations to the Asian country as they booked a date with Group A winners Uruguay./(TPF) "Mostly I feel disappointed and sad. /(FPF ) It is the results that count so there is not much to say he addEd./(TPF) I can only congratulate the South Koreans."/(FPF) (Sporting Life, June 23, 2010)

The third person focus predominates the text and next to it is the first person focus. The approbative element that features in the text is next to the first person focus in terms of frequency of occurrence. There is one instance each of the substantiating element, declarative element and pejorative element. There is no occurrence of Concessive element in the text. The occurrence of both approbative element and pejorative elements can be attributed to the occurrence of evaluation at the macrolevel of text. The dominance wielded by the third person focus is a result of the style employed by the writer in reporting the event. We have the use of nominal phrases and also the use of proper nouns which are associated largely with the third person focus in the text. Example of the nominal phrases are the 'Super Eagles' and 'Largerback' 'Obafemi Martins' as examples of where proper nouns are used in the structure of the third person focus in the text. This signifies and draws attention to notable individuals in the course of play.

\begin{tabular}{|c|c|c|c|c|c|c|c|c|}
\hline \multirow{2}{*}{ Text A5 } & \multirow{2}{*}{ Macrostructures } & \multicolumn{7}{|c|}{ Microstructures } \\
\hline & & FPF & TPF & $\mathrm{CE}$ & SE & $\mathrm{DE}$ & $\mathrm{AE}$ & $\mathrm{PE}$ \\
\hline 1. & Title & - & - & - & - & 1 & - & - \\
\hline 2. & Preamble & - & 1 & - & 1 & - & - & - \\
\hline 3. & Online Thesis & - & 2 & 1 & - & - & - & - \\
\hline 4. & Online Thesis Expatiation & 1 & 2 & - & - & - & - & - \\
\hline 5. & Winding Up & 1 & 1 & - & 1 & - & - & - \\
\hline & Total & 2 & 6 & 1 & 2 & 1 & 0 & 0 \\
\hline
\end{tabular}

Table 5: Microstructural Analysis of Text A5

Below are the microstructural elements identified in Text A5

1. Title: FIFA to Axe Nigeria Today /(DE)

2. Preamble: The future of Nigeria's football will be decided today by the world football governing body FIFA, as the country's President Goodluck Jonathan refused to back down on his decision to ban the national football team from international competition for two years./(TPF) With the sacking of Nigeria Football Federation (NFF) 
President, Sani Lulu, Vice President Amanze Uchegbulam, as well as a member of the federation's technical committee, Taiwo Ogunjobi, by the federation's executive committee, many football fans has hoped that the government might rescind its decision./(SE)

3. Online Thesis: A letter dated July 2 and signed by FIFA Secretary-General Jerome Valcke had warned that/(TPF) if this directive by the government is not withdrawn today before $5 \mathrm{pm}$ Nigerian time,/(CE) their emergency committee will meet and suspend Nigeria from international football with immediate effect./(TPF)

4. Online Thesis Expatiation: "We would like to underline the dire effects a suspension could have on the future of Nigerian football./(FPF) It would mean that no Nigerian team of any sort (including clubs) could have any international contracts," the letter said./(TPF) It would also mean that neither NFF nor any of its members of official could benefit from any development programmeme, course or training from FIFA or CAF any longer./(TPF)

5. Winding Up: We consider that this governmental decision would only completely isolate Nigerian football/(FPF) and could thus stall reforms and further development and improvement of Nigerian football for a long time./(SE) It puts the whole future of Nigerian football in danger./(TPF) (Sporting Life, July 5, 2010)

In the text above, the third person focus dominates the microstructural analyses of the text. It is realised across the macrostructural segment of text except the title where the declarative element realises the 'to infinitive clause'. First person focus and substantiating elements are next in frequency to the third person focus while there is an instance of the concessive element. Pejorative elements and approbative elements do not feature at all in the text. The absence of evaluation in this particular text may account for the non-occurrence of the approbative elements and pejorative elements.

\begin{tabular}{|c|c|c|c|c|c|c|}
\hline FPF & TPF & CE & SE & DE & AE & PE \\
\hline 101 & 420 & 28 & 116 & 36 & 10 & 1 \\
\hline
\end{tabular}

\section{Table 6: Microstructures Across Text A ( a total of thirty-six texts)}

The table above shows the realisation of microstructural elements across Text A. It is evident from the table that the third person focus is preponderant in Text A. It has the largest frequency and next to it is the substantiating element. First person focus also features significantly and this is followed by declarative element in terms of frequency of occurrence. Concessive element that features is followed by the approbative element while pejorative element has the lowest frequency in Text A. Therefore, all microstructural elements feature in Text $\mathrm{A}$ but with varried degree of occurrence.

\section{Microstructural Analysis of Text B (Complete Sports)}

This section is devoted to the microstructural analysis of Text $\mathrm{B}$. The analysis is done on all the selected texts and examples are presented from the data for sample analyses.

\begin{tabular}{|c|c|c|c|c|c|c|c|c|}
\hline \multirow{2}{*}{ Text B1 } & \multirow{2}{*}{ Macrostructures } & \multicolumn{7}{|c|}{ Microstructures } \\
\hline & & FPF & TPF & $\mathrm{CE}$ & SE & $\mathrm{DE}$ & $\mathrm{AE}$ & $\mathrm{PE}$ \\
\hline 1. & Title & - & - & - & - & 1 & - & - \\
\hline 2. & Preamble & - & 4 & - & 2 & - & - & - \\
\hline 3. & Online Thesis & - & 1 & - & - & - & - & - \\
\hline 4. & Online Thesis Expatiation & - & 1 & - & - & - & - & - \\
\hline 5. & Voice Insertion & 9 & 5 & - & 3 & - & - & - \\
\hline 6. & Prediction & 2 & 3 & - & 1 & - & - & - \\
\hline 7. & Winding Up & - & 1 & - & 1 & - & - & - \\
\hline & Total & 11 & 15 & 0 & 7 & 1 & 0 & 0 \\
\hline
\end{tabular}

\section{Table 7: Microstructural Analysis of Text B1}

Below are the microstructural elements identified in Text B1.

1. Title: Eagles: It's Win or Burst Today /(DE)

2. Preamble:Super Eagles stars say they are ready to spill blood if necessary to ensure they get the maximum points in today's must-win group B game against Greece at the Free State Stadium in Bloemfontein./(TPF)

The Nigerians who landed in Bloemfontein/Mangaung on Wednesday afternoon were welcomed by a cultural group to the isolated, mountain - side Bloem Spa Lodge and Conference Centre in the early afternoon/(TPF) with dancing and singing, in the sotho language./(SE)

Players and officials flew for nearly two hours from Richards Bay to the Free State Airport/(TPF), and all moved in convoy to the hillside hotel, which will be home for the next forty eight hours./(SE). The team trained at the 45,000 - capacity Free State Stadium from 5.30pm./(TPF)

3. Online Thesis: The players are however confident of defeating Greece in today's match to set up a potential winner-takes-all match against South Korea in their final group game in Durban./(TPF)

4. Online Thesis Expatiation: Enterprising forward, Ozase Odewingie believes the team's display against Argentina in the opening group game which they lost 1-0 has given them a psychological lift ahead of today's 
game./(TPF)

5. Voice Insertion (i): I'm happy enough with our approach against one of the best teams in the World./(FPF) We had our fair share of luck/(FPF) and it ended up a good evening for us./(TPF) I think we showed we have potential/(FPF) and proved we could go a long way/(FPF). We've lost a match at the World Cup,/(FPF) but I'm hearing that the folk back home are happy/(SE). We didn't play as well in attack as we'd hoped/(FPF), but it is good that we only conceded the one goal/(SE). It's going to be easier against the other teams starting with Greece,/(TPF) "he said./(TPF) Kalu Uche, the Almeria of Spain star man is also confident the Greeks will fall just the same way midfielder, Dixon Etuhu thinks albeit both say it won't be a stroll in the park for them./(TPF) Voice Insertion (ii): We all know what's at stake./(FPF) It's going to be a difficult match because the two sides need to win to boost their chances of qualifying from this group/(TPF). But I have confidence in our team to get the necessary result/(SE). We prepared both mentally and physically from this game/(FPF) and we're ready to come out with everything we've got. /(FPF)

6. Prediction: Etuhu says the Eagles will soar above the Greeks today and hopes the result will go Nigeria's way./(TPF) 'We all know what we must do on Thursday,/(FPF) it's victory or nothing and I'm glad/(FPF) we're ready to fire from all cylinders/(FPF). Hopefully, the result will go our way'./(TPF). Nigeria beat Greece 2-0 at the 1994 FIFA World Cup in the USA, in the two teams' only previous World Cup meeting,/(TPF) with goals from Finidi George and Daniel Amokachi, both goals coming at stoppage time of each half./(SE)

7. Winding Up: Coach Lars Largerback has a full squad to choose from on Thursday evening/(TPF), and has hinted at likely changes in the starting line-up that featured against Argentina on Saturday/(SE). (Complete Sports, June 17, 2010)

Third person focus is preponderantly used in Text B1. It features in almost all the macrostructures of Text B1. Next to the third person focus in terms of frequency is the first person focus which is largely associated with voice insertion. Substantiating element and declarative elements also feature. Pejorative element and approbative element do not feature. This may be as a result of the non-occurrence of evaluation - a macrostructural element. A cusory look at the text says so much about the earlier claim made on voice insertion as a recursive macrostructural element of text. It appears in such a way that it takes a good understanding and sense of identification to locate the other macrostructures such as prediction and winding up in the text.

\begin{tabular}{|l|l|r|r|r|r|r|r|r|}
\hline \multirow{2}{*}{ Text B2 } & \multirow{2}{*}{ Macrostructures } & \multicolumn{9}{c|}{ Microstructures } \\
\cline { 3 - 10 } & Title & FPF & TPF & CE & SE & DE & AE & PE \\
\hline 1. & Preamble & - & - & - & - & 1 & - & - \\
\hline 2. & Online Thesis & - & 2 & - & - & - & - & - \\
\hline 3. & Online Thesis Expatiation & - & 15 & - & 1 & - & - & - \\
\hline 4. & Total & 0 & 19 & 3 & 3 & - & - & - \\
\hline \multicolumn{7}{|l}{} \\
\hline
\end{tabular}

Table 8: Microstructural Analysis of Text B2

Below are the microstructural elements identified in Text B2.

1. Title: WASTEFUL EAGLES CRASH OUT OF W/CUP/(DE)

2. Preamble: South Korea will play Uruguay in the last 16 of the World Cup after their 2-2 draw with Nigeria proved enough to secure the runners-up spot in Group B./(TPF)

Kalu Uche gave Nigerian an early lead in Durban but South Korea turned the game on its head via goals from Lee Jung-Soo and Park Chu-Young./(TPF)

3. Online Thesis: Yakubu Aiyegbeni restored parity from the penalty sport, moments after producing one of the most glaring misses in the World Cup history,/(TPF) but the point was not enough for the Nigerians, who failed to win any of their games in South Africa./(SE)

Progression for Huh Jung-Moo's men marked history for the country as for the first time they reached the second round on foreign Soil./(TPF)

4. Online Thesis Expatiation: Lars Lagerback awarded veteran striker Nwakwo Kanu a first World Cup start,/(TPF) while Yusuf Ayila, Rabiu Afolabi and Chinedu Obasi were also drafted in./(CE) For South Korea, Hug Jung-Moo made one change to the side which lost 4-0 Against Argentina, switching Oh Beom-Seok for Cha Doo-Ri./(TPF)

The South Koreans almost got off to a dream start when an attack down the right saw Lee Chung-Yong threaded in on goal./(TPF) But the Bolton midfielder's sliding effort zipped wide of the near post./(SE) Then, Ki Sung-Yong had a sighter from range but saw his striker blaze over./(TPF) On 12 minutes, seemingly out of nothing, Nigeria went in front./(TPF) Chidi Odiah raced down the right and drove in low cross./(TPF) South Korea right back $\mathrm{Cha} \mathrm{Du}$-Ri was half-asleep to allow Uche to storm in the fire in his second goal of the 2010 World Cup./(TPF)

South Korea were noticeably reeling from their concession of the opening goal as Nigeria threatened to double their lead./(TPF) In the $22^{\text {nd }}$ minutes, Uche fired a free-kick over the bar before Chinedu Obasi opted to shoot off target when he really should have crossed to his team -mates lurking at the far post./(TPF) 
Huh's side looked to respond via a clever ball from Park Ji-Sung,/(TPF) but Park Chu-Young's finish was tepid./(SE) Nigerian's reaction was to put together a fine move, with passing a plenty./(TPF) However, it was concluded with a rather central shot from Obasi, ensuring Jung Sung-Ryong saved with ease./(CE)

Jung's goalkeeping counter-part Vincent Enyeama then found himself in the thick of the action when he came charging out of his area before being booked for a foul on Park Jo-Sung near the touchline./(TPF) The resulting free-kick was curling inwards by Ki Sung Yong and convincingly punched out by Enyeama./(TPF)

South Korea's woodwork was then left rattling by an Uche's strike,/(TPF) but, against the run of the play,/(SE) they found themselves levels./(TPF) Obasi fouled and was given a yellow card and Ki Sung-Yong's cross into the box from the free-kick was diverted home by Lee Jung-Soo for his second goal in South Africa,/(TPF) although luck was on his side as he meant to head the delivery by instead notched in via his leg./(CE) (Complete Sports, June 23, 2010)

Third person focus dominates the other macrostructures in the text. It has the highest frequency of occurrence and next to it is the substantiating element. Concessive element also features and the declarative has the lowest occurrence. Meanwhile, first person focus does not feature at all in Text B2 which confirms less of the imput of the writer. Approbative element and pejorative did not feature as a result of the absence of evaluation in the macrostructure.

Talking about the characteristic features of third person focus in the analysis of this text, the writer uses them across the macrostructural units to highlight the personality mentioned except in the title which is realised by declarative element. Examples of nominal phrases and proper nouns are 'the South Koreans', and 'Lars Lagerback' respectively.

\begin{tabular}{|l|l|c|c|c|c|c|c|c|}
\hline \multirow{2}{*}{ Text B3 } & \multicolumn{6}{|c|}{ Macrostructures } & \multicolumn{6}{c|}{ Microstructures } \\
\cline { 2 - 9 } & & FPF & TPF & CE & SE & DE & AE & PE \\
\hline 1. & Title & - & - & - & - & 1 & - & - \\
\hline 2. & Preamble & & 1 & - & - & - & - & - \\
\hline 3. & Online Thesis & - & 1 & - & - & - & - & - \\
\hline 4. & Online Thesis Expatiation & 3 & 1 & - & & - & - & - \\
\hline 5. & Voice Insertion & 3 & & - & - & - & - & - \\
\hline 6. & Winding Up & - & 1 & - & - & - & - & - \\
\hline & Total & 6 & 4 & 0 & 0 & 1 & 0 & 0 \\
\hline
\end{tabular}

\section{Table 9: Microstructural Analysis of Text B3}

Below are the microstructural elements in Text B3.

1. Title: Enyeama: I'm DisappointEd./( DE)

2. Preamble: Super Eagles goalkeeper, Vincent Enyeama was completely devastated in the aftermath of Nigeria's elimination from the on-going 2010 World Cup after playing a 2-2 draw with South Korea inside Moses Mabhida Stadium, Durban last night./(TPF)

3. Online Thesis: The Hapoel Tel Aviv shot stopper who emerged as the Man-of-the Match in the first two games against Argentina and Greece was of the view that the team's performance was a bit let down for the soccer loving Nigerians who have been supporting the team all the while and of course, the entire African continent./(TPF)

4. Online Thesis Expatiation: The former Enyimba goalie said with a tone of dejection and disenchantment./(TPF) "I am short of words,/(FPF) it is so bad/(FPF) I must confess,"/(FPF)

5. Voice Insertion : "I don't know how to explain this except to say that we are very sorry to our fans back at home./(FPF) The truth is that we let ourselves down/ (FPF) and I am sure that the continent of Africa would be disappointed by the performances of African teams in this tournament."/(FPF)

6. Winding Up: The coach Lars Lagerback tortured side failed to take advantage of Argentina 2-0 win over Greece in the other match and ended the World cup with just one point in the 3 matches./(TPF) (Complete Sports: June 23, 2010)

First person focus dominates the microstructures in the text and next in frequency of occurrence is the third person focus. The title is realised by the declarative element, while other microstructural elements do not feature at all. This could be tied to the fact that the writer and the participants involved could not give reasons for their failure or for disappointing their fans. The dominance of the first person focus is as a result of the realisation of voice insertion of the macro level of text structure. 


\begin{tabular}{|l|l|r|r|r|r|r|r|c|}
\hline \multirow{2}{*}{ Text B4 } & \multicolumn{1}{|c|}{ Macrostructures } & \multicolumn{9}{c|}{ Microstructures } \\
\cline { 3 - 9 } & & FPF & TPF & CE & SE & DE & AE & PE \\
\hline 1. & Title & - & - & - & - & 1 & - & - \\
\hline 2. & Preamble & - & 2 & 1 & - & - & - & - \\
\hline 3. & Online Thesis & - & 2 & 1 & - & - & - & - \\
\hline 4. & Online Thesis Expatiation & - & 9 & 1 & 2 & - & - & - \\
\hline \multicolumn{2}{l}{ Total } & 0 & 13 & 3 & 2 & 1 & 0 & 0 \\
\hline
\end{tabular}

Table 10: Microstructural Analysis of Text B4

Below are the microstructural elements in Text B4.

1. Title: EAGLES GET \$30K BONUS OFFER TO BEAT S/KOREA /(DE)

2. Preamble : The Nigeria Football Federation, NFF, have promised to pay 30,000 dollars each to each member of the Super Eagles/(TPF) if they beat South Korea on Tuesday and qualify for the Round of 16 of the 2010 World Cup,/(CE) top team official, Taiwo Ogunjobi revealed to Complete Sports./(TPF)

3. Online Thesis: Despite having lost their first two matches victory for Nigeria in its win-or-burst Group B match in Durban, coupled with an Argentina win over Greece, would propel Super Eagles to the knockout stage of the tournament./(TPF)

Each player was told they would get 10,000 dollars for every victory in the first round of the World Cup/(TPF). But no one is smiling yet to the bank as the team has yet to win a game in South Africa./(CE)

4. Online Thesis Expatiation: However, an additional incentive to the team to beat South Korea/(CE), the Nigeria Football Federation (NFF) have now agreed to pay the team not on a match-to-match basis,/(TPF) but on the basis of qualification for each round of the competition./(SE). "The players will now each pocket 30,000 dollars each if they beat Korea and qualify for the next round/(TPF). It was something the NFF leadership agreed with the players," said Ogunjobi in a telephone chat with Complete Sports./(TPF). The Eagles will earn a further 12,500 dollars per had for victory in the Round of 16./(TPF)

Nigeria Football Federation (NFF) President Sani Lulu has urged the team to win against South Korea/(TPF). He addressed the team before training on Friday/(TPF), urging them to rise to the occasion as the whole country still believes in them./(SE)

On Sunday afternoon, coach Lars Lagerback shut out both the media and officials of the NFF from his training as he finalized plans ahead of Tuesday's game./(TPF)

According to NFF spokesman Ademola Olajire it was the first time since the tournament kicked off that NFF staffers were banned from the team's training./(TPF) "Lagerback decided to close the session entirely to media and other persons outside the team and technical personnel in order to try out new formations and strategies," said Olajire/(TPF). (Complete Sport, June 21, 2010)

From table 10, it is clear that the writer uses the third person focus more than any other micro-rhetorical elements of text. The concessive element is next to the third person focus in terms of frequency of occurrence. Substantiating element also features while the declarative element has the lowest frequency of occurrence. The first person focus does not feature at all and likewise approbative and pejorative elements of text structure.

Talking about the characteristic feature of the third person focus in this particular text, the writer uses the linguistics properties such as the nominal phrases, third person pronouns 'he', and the cleft 'it' in the textual structure where the third person focus occurs to present the narration which gives less of the personal imput to the writer. This is usually done wherever the writer wants to detach himself / herself from the reports or narration.

\begin{tabular}{|l|l|c|c|c|c|c|c|c|}
\hline \multirow{2}{*}{ Text B5 } & \multicolumn{1}{|c|}{ Macrostructures } & \multicolumn{6}{c|}{ Microstructures } \\
\cline { 3 - 10 } & & FPF & TPF & CE & SE & DE & AE & PE \\
\hline 1. & Title & - & - & - & - & 1 & - & - \\
\hline 2. & Preamble & 2 & 5 & - & 2 & - & 1 & - \\
\hline 3. & Online Thesis & - & 6 & - & 1 & - & - & - \\
\hline 4. & Online Thesis Expatiation & - & 10 & - & 1 & - & - & - \\
\hline 5. & Evaluation & - & - & - & & - & 2 & - \\
\hline 6. & Winding Up & - & 1 & - & - & - & - & - \\
\hline \multicolumn{2}{l}{ Total } & 2 & 22 & 0 & 4 & 1 & 3 & 0 \\
\hline
\end{tabular}

Table 11: Microstructural Analysis of Text B5

Below are the microstructural elements in Text B5.

1. Title: Eagles Crash: NFF Have Lots of Questions to Answer /(DE)

2. Preamble : In the rest room of the Durban Airport at about midnight on the day Nigeria delivered the best 'miss' of the World Cup to the 2010 Championship, a young man confronts me and says: Sorry about today's loss/(TPF). Your players played well/(AE) but were unlucky/(SE). They could have won the match,/(TPF) but any team that create as many chances as they did today and fails to win does not deserve to remain in the championship'/(SE). I think about that for a few seconds/(FPF). It is painful/(TPF) but it makes sense. Teams 
survive at this level of competition by taking the few chances that come their way in matches/(TPF). Teams cannot afford to lose chances and hope to make progress/(TPF). I am thinking about the match all over again and what it means for Nigeria and, indeed, for Africa/(FPF).

3. Online Thesis: Nigerians do not appreciate how the rest of the world respects their country in football until they go out and listen to the global football stakeholders/(TPF). Sepp Blatter has joined others here in lamenting Nigeria's premature exit/(TPF). Issa Hayatou is reportedly distraught with the fall of Nigeria/(TPF). Heinz Marotzske is hugely disappointed and angry/(TPF). Everyone here just cannot understand how Nigeria could have let slip from their hands what fate had so graciously presented them on a platter/(TPF). Till now it is still cofounding, bizarre and baffling how a country that lost its first two group matches could still have qualified by winning the third and last match with any score line/(SE). That was the situation the Eagles found themselves in last Tuesday night with the 61,800 spectators at the stadium, 150 million Nigerians/(TPF), and the entire continent rooting for them to win and save Africa the almost certain humiliation that would follow should none of the continent's 6 representatives go beyond the first round./(SE)

4. Online Thesis Expatiation: Lars Lagerback, in an apparent display of sufficient knowledge of the Nigerian players, put Rabiu Afolabi, a right-footed player whose left foot is only good for standing on, at left back/(TPF). It turned out a poor decision as Nigeria concede the first goal as a result of his poor marking from a set piece. In a match that the Eagles could have easily won, they handed back to fate what it had so generously and undeservedly presented to them./(TPF) Aiyegbeni's miss, one meter from an open goal, may find a place in the Guinness Book of World Records as one of the greatest misses of any World Cup/(TPF). Some analyst said that it was easier to score the goal than to miss it/(TPF) It is bound to haunt him forever/(TPF). Obafemi Martin's late chip that went also wide and denied Nigeria a possible third goal that would have made all the difference is another failed attempt that would haunt the country for sometimes to come./(TPF) The conversation amongst Nigerians here of all walks of life is that there is an urgent need for reforms in Nigerian football/(TPF). The reforms should include a new leadership for the football association, a permanent coach for the national team/(TPF), a new generation of players for the national team, and a return to the football development as a focus of Nigerian football for some years to come./(SE) What is not in dispute is that the present NFF must not return to continue the 'legacy' they are bequeathing to Nigerians as they depart the World Cup on the eve of the end of their tenures/(TPF) The challenge is how to effect that change, without interfering with the statues of the federation and attracting the ire of FIFA that have been desperately but cleverly drawn into the matter by the NFF./(TPF) .

5. Evaluation: The Super Eagles played fairly well but very determinedly./(AE) Right back, Chidi Odiah, was easily and surprisingly the best player on the night/(AE).

6. Winding Up : As Nigerians return home to face the pain of their loss the football house would have lots of questions to answer/(TPF) (Complete Sports, June 26, 2010)

This text is a particularly long one as it relays the loss and consequences of the loss of the Nigerian Super Eagles at the 2010 world cup. The high frequency of occurrence of TPF is understandable especially in the online thesis expatiation where a long explanation has to be given for the unfortunate loss. It can be inferred from the table that the text is dominated by third person focus as a semantic structure. Substantiating element is next to it in frequency while approbative element is also next to the substantiating element. The declarative element has the lowest degree of occurrence while the concessive element and pejorative element do not feature at all. It is probably not the time to apportion blame or make serious negative comments. Third person focus is realised in all the macrostructures except in the title where declarative element features. It occurs more in the structure of online thesis expatiation where the writer elabourates more on the thesis of the text.

\begin{tabular}{|c|c|c|c|c|c|c|}
\hline FPF & TPF & CE & SE & DE & AE & PE \\
\hline 85 & 436 & 30 & 92 & 36 & 7 & 2 \\
\hline
\end{tabular}

\section{Table 12 : Microstructures Across Text B (a total of thirty-six texts)}

From the microstructural analysis of all the texts in Text B, third person focus has the highest frequency of occurrence. Substantiating element is next to it in terms of frequency and next to the substantiating element is first person focus. Declarative element also features to an appreciable extent across Text B and next to it in terms of frequency is the concessive element. Approbative element also features in Text B and the pejorative element has the lowest degree of occurrence. It is to be noted that all microstructural elements feature in Text B and this is obtainable in Text $A$ as well but with varied degree of frequency.xxxxxxxxxxxxxxxx CORRECT THE TABLE AFTER DELETING TEXT C AND ALSO EDIT THE PERCENTAGE IN THE DISCUSSION THAT FOLLOWS THE TABLE 


\begin{tabular}{|c|c|c|c|c|c|c|c|c|c|c|c|c|c|c|}
\hline \multirow{2}{*}{ TEXT } & \multicolumn{14}{|c|}{ MICROSTRUCTURAL ELEMENTS, FREQUENCY AND PERCENTAGE DISTRIBUTION } \\
\hline & FPF & $\%$ & TPF & $\%$ & $\mathrm{CE}$ & $\%$ & SE & $\%$ & $\mathrm{DE}$ & $\%$ & $\mathrm{AE}$ & $\%$ & PE & $\%$ \\
\hline Text A & 101 & 54.30 & 420 & 49.07 & 28 & 48.30 & 116 & 55.77 & 36 & 50 & 10 & 58.82 & 1 & 33.33 \\
\hline Text B & 85 & 45.70 & 436 & 50.93 & 30 & 51.70 & 92 & 44.23 & 36 & 50 & 7 & 41.18 & 2 & 66.67 \\
\hline Total & 186 & 100 & 856 & 100 & 58 & 100 & 208 & 100 & 108 & 100 & 17 & 100 & 3 & 100 \\
\hline
\end{tabular}

Table 19: Realisation of Microstructural Elements Across Texts A, B and C (the three sets of texts)

The table above shows the total frequency and percentage distribution of microstructural elements across the data. A cursory look at the table reveals that all microstructures identified feature across the data but the third person focus has the highest frequency and it is realised at different percentages across texts A-B. In Text A, third person focus has $49.07 \%$. It has $50.93 \%$ in Text B. Third person focus has the highest frequency in Text B. All other microstructures feature across the data too but with variation in terms of frequency. The table reveals that pejorative element has the lowest frequency of distribution across Texts A-B

\section{Conclusion}

The study has been able to analyse the microstructures of selected football texts. It relates the macrostructures with microstructures of text structure for identification and description of the semantic relations of text content. The study concludes that macrostrural and microstructural analysis of texts give a better understanding of text. It helps in revealing the detailed information about the organisational textual structure and the semantic relationship of different textual units. Understanding of textual organisational structure and contents illuminate the message projection of texts.

\section{References}

Adegbija, E. (1995) 'I Major General X: Discourse Tacts in Military Coup Speeches'.Text 15 (2) 253-270.

Adegbite, W. (1991) 'Some Features of Language Use in Yoruba Traditional Medicine.' An Unpublisbed Ph.D Thesis, University of Ibadan, Ibadan.

Adegbite, W. and Ajayi, B. (1995) 'Thematic Progression and the Structure of Yoruba Divinatory and Incantatory Texts' In Adediran, B. (Ed.) Cultural Studies in Ife. 175-192.

Eggin, S. and Slade, D. (1997) Analysing Casual Conversation. London: Cassell.

Hutchins, J. (2002) 'From Text Linguistics to a Human Linguistics of Texts: The Scientific Paper as a Case Study’ (www.hutchinsweb.me.uk/HSL 2002.pdf Accessed 18/2/14)

Lawal, R.A. (1997) Sylistics in Theory and Practice. Ilorin: Paragon Books.

Louwerse, M. M \& Graesser, A.C. (2006) 'Macrostructures' in E.K. Brown (Ed.) The Encylopedia of Language and Linguistics. Amsterdam, Elsevier.

Odebunmi, A. (2006) 'A Pragmatic Reading of Yerima's Proverb in 'Yemoja Attahiru' and 'Dry Leaves on Ukan Trees'. Intercultural Pragmatics 3, 2: 153-170.

Olagunju, S. (2004) 'Thematic and Functional Elements in Ojo Ade's The Almond Tree'.Africa: Journal of Contemporary Issues. Vol. 2 No. 2, 236-252.

Olagunju, S. \& Ogunleye, K. (2007) 'Thematic Structure in Isaiah 49'. Odebunmi, A. and Babajide A. O (Eds.). Style in Religious Communication in Nigeria. Germany, Lincom Europa, 107-123.

Olateju, M.A. \& Yusuf, Y.K. (2006) Back Channel Communication in Ola Rotimi's Our Husband Has Gone MadAgain. Nordic Journal of African Studies. 15 (4): 520-535.

Sadeghi, L. (2013) 'From Macro and Microstructures to an Innovation: The Macrofiction Structure'. International Journal of English Language and Linguistic Research. Vol. 1, No2, 13-30.

van Dijk, T.A. (1973) 'A Note on Linguistic Macrostructure' In A.P ten Cate \& P.Jordens (Eds.), Linguistiche Perpektiven.Tubingen:Niemeger.

(1980) Macrostructures. New Jersey: Lawrence Erlbaum Associate Publishers.

van Dijk,T.A. and Kintsch, W. (1983) Strategies of Discourse of Comprehension. New York:

Academic Press.

van Dijk,T.A. (1986) News as Discourse. University of Armsterdam, Department of General

Literary Studies, Unpublished Book. .Ms.

(1988) News as Discourse. Hillsdale, N.J. : Lawrence Erlbaum.

(1990) The Future of the Field: Discourse Analysis in the 1990s'. Text 10 (1/2) 133-156

(1993b) Principles of Critical discourse analysis. Discourse and Society 4(2), 249-83.

(1998) Ideology.London: Sage.

(2001) 'Discourse, Ideology \& Context'. Folia Linguistica xxx/1-2, 11-40. 